\title{
GAIT SPEED AND HOSPITAL REINTERNATION AFTER CORONARY ARTERY BYPASS GRAFTING
}

\author{
Andrea Santos ${ }^{1}$, Thais Soares ${ }^{1}$, André Guimarães ${ }^{2}$, Lucas Cacau ${ }^{3}$, and André Luiz Lisboa \\ Cordeiro $^{1}$ \\ ${ }^{1}$ Faculdade Nobre \\ ${ }^{2}$ Instituto Nobre de Cardiologia \\ ${ }^{3}$ Federal University of Sergipe
}

October 9, 2020

\begin{abstract}
Introduction: Gait speed can be applied, predicting outcomes associated with hospital stay such as length of stay and/or discharge. Despite these studies that correlate gait speed with the aforementioned outcomes, when we deal with cardiac surgery there is a gap. Objective: Verify whether gait speed is associated with the risk of hospital readmission in the postoperative period of coronary artery bypass grafting. Methodology: This is a prospective cohort study. In the preoperative period, all patients underwent a 10-meter gait speed test and repeated at hospital discharge. After the repetition of the gait speed test, patients were divided into two groups: slow and non-slow. Those who were not discharged walked less than $1.0 \mathrm{~m} / \mathrm{s}$ occupied the slow group and those who were above $1.0 \mathrm{~m} / \mathrm{s}$ were classified as not slow. Patients were followed for six months to observe the primary outcome, which was the need for hospital readmission. Results: The 6 months rate of readmission was $58 \%(14 / 24 ; 95 \%$ CI $49 \%$ to $80 \%)$ among slow walkers and $17 \%(6 / 36 ; 95 \%$ CI13\%to46\%) among non-slow walkers $(p=0.002)$.In univariate analysis, gait speed, treated as a continuous variable, was associated with the primary outcome (HR0.6;95\%CI0.2to0.9), while age, gender, BMI, MV and CPB time were not. In the multivariate model including age, gender, BMI, MV and CPB time, gait speed remained the only variable associated with readmission (multivariate HR:0.5,95\%CI0.1to0.7p=0.02). Conclusion: Our data suggest that gait speed is associated with hospital readmission in patients undergoing to coronary artery bypass grafting.
\end{abstract}

\section{INTRODUCTION}

In recent years, heart disease has increased considerably, causing a large number of surgical procedures that aim to increase patient survival ${ }^{1}$. There are several risks and complications of this form of treatment that can interfere in pulmonary capacity and physical performance, reducing the functionality of patients. The decrease in daily activities of life due to prolonged hospitalization can also lead to several neuromuscular, pulmonary, functional and quality of life problems ${ }^{2}$.

Patients after cardiac surgery tend to have muscle weakness due to lack of movement, loss of physical conditioning, inflammation, use of drugs such as corticosteroids, muscle relaxants, neuromuscular blockers, antibiotics and in the presence of associated neuromuscular syndromes ${ }^{3}$. This weakness may be associated with decreased walking speed in the postoperative period, with this variable being associated with worse outcomes such as mortality and hospital readmission in other profiles such as hypercapnic heart and respiratory failure $^{4,5}$.

Gait speed can be assessed using the 10-meter test ${ }^{6}$. This test can be applied preoperatively, predicting outcomes associated with hospital stay such as length of stay and/or discharge ${ }^{7,8}$. Changes in the organism with the surgical procedure cause a decline in the patient's functional activities in the postoperative phase, 
making walking a complex skill, as gait speed tends to decrease due to the physiological changes that occur such as the reduction of muscle strength ${ }^{9}$.

Despite these studies that correlate gait speed with the aforementioned outcomes, when we deal with cardiac surgery there is a gap. This answer can be useful for making decisions and directing appropriate intervention to minimize these adverse results. The aim of this study was to verify whether gait speed is associated with the risk of hospital readmission in the postoperative period of coronary artery bypass grafting.

\section{MATERIAL AND METHODS}

\section{Study design}

This is a prospective cohort study that was conducted between January 2018 and July 2019, in patients undergoing to CABG at the Instituto Nobre de Cardiologia / Santa Casa de Misericórdia, in the city of Feira de Santana (BA). The research was approved by the Research Ethics Committee of Faculdade Nobre, under number 796,580 and the patients were included after signing the informed consent form.

\section{Eligibility criteria}

Patients aged over 18 years, of both sexes, submitted to coronary artery bypass graft surgery who used cardiopulmonary bypass and median sternotomy were included. Individuals with some physical limitation, such as sequelae of stroke and lower limb amputation, uncontrolled arrhythmias, changes in blood pressure at the time of the test (SBP $<80$ or $>160 \mathrm{mmHg}$ ), angina, electrocardiographic changes were excluded.

\section{Study protocol}

In the preoperative period, all patients included in the survey underwent a 10-meter walk test. The following day, everyone underwent a surgical procedure, was referred to the Intensive Care Unit (ICU) and, being discharged, was directed to the inpatient unit. In all these moments, they received routine care from the unit without any influence from the researchers. All patients were assisted by the physiotherapist on duty and performed breathing exercises, orthostasis training on the first postoperative day, sitting in the chair and ambulation on the second postoperative day when there was no clinical contraindication (use of vasoactive drugs, uncontrolled pain or infectious changes). On the day of hospital discharge, patients repeated the 10 -meter test.

After the repetition of the gait speed test, patients were divided into two groups: slow and non-slow. The cutoff point used was $1.0 \mathrm{~m} / \mathrm{s}$ based on the study by Odonkor et al. ${ }^{10}$ Those who were not discharged walked less than $1.0 \mathrm{~m} / \mathrm{s}$ occupied the slow group and those who were above $1.0 \mathrm{~m} / \mathrm{s}$ were classified as not slow. Patients were followed for six months to observe the primary outcome, which was the need for hospital readmission. There was a comparison between the groups of the initial, final butch speed, delta velocity, cardiopulmonary bypass (CPB), mechanical ventilation (MV), Intensive Care Unit (ICU) time and hospital stay. It is worth mentioning that readmission in any hospital was counted for this study, patients were contacted by telephone seeking this type of information.

\section{Measuring instruments}

The 10-meter speed test took place in a corridor with no movement of people. A space of 14 meters was used, the first two for acceleration and the last two for deceleration ${ }^{6}$. Therefore, the 10 meters were used to assess speed. The test was performed three times and an average of the three values was calculated. Before and after each repetition, the patients had their vital signs checked.

For the test, a chronometer was also used, evaluating the time the patient needed to walk for 10 meters and expressed in meters/second ${ }^{7}$ (Figure 1 ). All repetitions were performed by a single examiner.

\section{Statistical analysis}

We then adjusted the association of gait speed with the primary outcome by using a multivariable Cox proportional hazards model adjusting for age, BMI and sex, and additionally adjusting for clinically relevant 
covariates (MV and CPB time). All tests for statistical significance were two-tailed with an alpha level of 0.05. Analyses were conducted using SPS version 20.0 and $\mathrm{R}$ version 2.14.113.

\section{RESULTS}

During the research period 71 patients were admitted, and fifteen were excluded due to physical limitations. Thus, 56 patients were evaluated, of these $38(63 \%)$ were male, mean age $61 \pm 9$ years, with an average BMI of $27 \pm 5 \mathrm{~km} / \mathrm{m} 2$, with the most prevalent comorbidity being sedentary with $19(63 \%)$. The other data are shown in table 1.

The average walking speed in the slow group was $0.6 \mathrm{~m} / \mathrm{s}$, while in the non-slow group it was $1.2 \mathrm{~m} / \mathrm{s}$. Twenty patients (40\%) were readmitted to the hospital during the observation period of 6 months. Of those, $14(70 \%)$ were slow walkers, as defined by a gait speed of less than $1.0 \mathrm{~m} / \mathrm{s}$, and $6(30 \%)$ were non-slow walkers. The 6 months rate of readmission was $58 \%$ (14/24; $95 \%$ CI $49 \%$ to $80 \%)$ among slow walkers and $17 \%(6 / 36 ; 95 \%$ CI $13 \%$ to $46 \%)$ among non-slow walkers $(\mathrm{p}=0.002)$.In univariate analysis, gait speed, treated as a continuous variable, was associated with the primary outcome (HR 0.6; 95\%CI 0.2 to 0.9 ), while age, gender, BMI, MV and CPB time were not (table 2). In the multivariate model including age, gender, BMI, MV and CPB time, gait speed remained the only variable associated with readmission (multivariate HR: $0.5,95 \%$ CI 0.1 to $0.7 \mathrm{p}=0.02$; table 2 ).

\section{DISCUSSION}

Based on the results of this prospective cohort study, gait speed was associated with hospital readmission of patients undergoing to coronary artery bypass grafting. Walking more slowly $(<1 \mathrm{~m} / \mathrm{s})$ was associated with hospital readmission, but variables such as age, male gender, BMI, MV and CPB team were not related to the outcome in six months.

Previous studies suggest that gait speed is an independent variable for mortality and hospital readmission in survivors of acute hypercapnic respiratory failure and heart failure ${ }^{11,12}$. Being an extremely simple and feasible test for the application of the practice, we suggest its adoption by hospital services aiming at reducing hospital readmissions, thus minimizing costs, improving the survival and quality of life of these patients.

Afilalo et al. demonstrated that patients with low gait speed in the preoperative period have a higher rate of morbidity and mortality during the ICU stay ${ }^{13}$. They also found that factors such as female gender and diabetics made up the slow speed group. In our study, we did not find any difference regarding gender, age or comorbidities, which may be associated with a smaller sample size in the present study. This result only reinforces the need to stratify patients with a higher risk of complications or hospital readmission, and gait speed is a useful tool.

In this rationale Sawatzky et al. ${ }^{14}$ found that the application of a program in the preoperative period can increase gait speed, with this effect remaining for up to three months after the procedure. On the other hand, Cerqueira et al. ${ }^{15}$ did not demonstrate any impact when applied to neuromuscular electrical stimulation in the postoperative period.

A possible explanation for reducing gait speed and increasing the risk of hospital readmission is fragility. It is considered a multidimensional syndrome resulting from the reduction of physiological reserves and an increase in physical and functional decline when exposed to external stressors ${ }^{16}$. After cardiac surgery, factors such as cardiopulmonary bypass, surgical incision, pleurotomy and duration of mechanical ventilation generate pulmonary dysfunction and decrease in physiological reserves ${ }^{17}$.

Bed restriction time and contributes to physical and functional decline ${ }^{18,19}$. Our group demonstrated that after myocardial revascularization it generates a decrease in functional capacity, observed through the sixminute walk test ${ }^{20}$. We found that performing inspiratory muscle training helps to minimize this decline and improve clinical outcomes such as length of hospital stay ${ }^{20,21}$. 
Lal et al. $^{22}$ demonstrated that the frailty assessed using the Edmonton scale is a predictor for the length of hospital stay and risk of readmission up to twelve months in elderly patients undergoing cardiac surgery. The combination of frailty assessment with gait speed will give the therapist fundamental information for the organization of an intervention protocol.

In Castro et al. ${ }^{23}$, it was evidenced that the greater distance covered in the $6 \mathrm{MWT}$ was associated with a shorter hospital stay, as a quick recovery after the surgical procedure allows walking autonomy that allows the transfer of this patient earlier for rehabilitation, and consequently reduce hospitalization time. In the study by Aikawa et al. ${ }^{24}$, they say that immediate post-surgical rehabilitation can be a means that enables the more agile development and recovery of these patients and found in the 6MWT that there was a significant increase in the distance covered and gait speed of these patients. Thus, comparing the studies presented, it can be understood that an early rehabilitation of patients after CABG is linked to a shorter hospital stay, consequently generating an improvement in gait speed when evaluated by the 6MWT.

According to Oliveira et al. ${ }^{25}$, it was evaluated that the CPB time has minimal influence on the patient's ability to walk, the research shows that despite the occurrence of muscle inefficiency, generating a loss of postoperative strength, it does not interfere in the gait of patients themselves. Reinforcing with the results of this study, we analyzed that the CPB time had no correlation with the patients' gait, as it statistically had no influence.

Borges et al. ${ }^{26}$ showed that patients undergoing cardiac surgery suffer adverse risks during hospitalization in the postoperative period, where they become more fragile due to some physiological changes that occur during the intervention, such as: motor disabilities and physical limitations that can be prolonged, and consequently, which may lead to future readmissions, the author also identified a vicious cycle of slow gait after surgery. The results of this study were similar to ours, in which it showed that patients undergoing CABG showed a decrease in gait speed due to several associated and already mentioned factors, and that it may possibly be associated with the risk of a hospital readmission.

The limitations of this study include the sample calculation, limiting the extent of its findings, absence of information on pulmonary function, which may have an influence on the performance of the gait speed test and the lack of a spirometric test.

\section{CONCLUSION}

Our data suggest that gait speed is associated with hospital readmission in patients undergoing to coronary artery bypass grafting.

\section{REFERENCES}

1. Cordeiro ALL, Brito AAOR, Santana NMA, Silva INMS, Nogueira SCO, Guimarães ARF, et al. Analysis of functional pre degree of independence and tall in ICU patients undergoing cardiac surgery. Revista Pesquisa em Fisioterapia. 2015;5(1):21-27

2. Fonseca L, Vieira FN, Azzolin KO. Fatores associados ao tempo de ventilação mecânica no pós-operatório de cirurgia cardíaca. Rev Gaúcha Enf. 2014;35(2):67-72.

3. Jesus FS, Paim DM, Brito JO, Barros IA, Nogueira TB, Martinez BP, et al. Mobility decline in patients hospitalized in an intensive care unit. Rev Bras Ter Intensiva. 2016;28(2):114-119

4. Karege G, Zekry D, Allali G, Adler D, Marti C. Gait speed is associated with death or readmission among patients surviving acute hypercapnic respiratory failure. BMJ Open Respir Res . 2020;7(1):e000542. doi:10.1136/bmjresp-2019-000542.

5. Nakamura T, Kamiya K, Hamazaki N, et al. Quadriceps strength and mortality in older patients with heart failure [published online ahead of print, 2020 Jul 2]. Can J Cardiol . 2020;S0828-282X(20)30582-1. doi:10.1016/j.cjca.2020.06.019. 
6. Fritz S, Lusardi M. White paper: "walking speed: the sixth vital sign". J Geriatr Phys Ther. 2009;32(2):469. http://dx.doi.org/10.1519/00139143-200932020-00002.

7. Studenski S, Perera S, Patel K, et al. Gait speed and survival in older adults. JAMA 2011;305:50-8.

8. Kahlon S, Pederson J, Majumdar SR, et al. Association between frailty and 30-day outcomes after discharge from hospital. CMAJ. 2015;187:799-804.

9. Jones SE, Maddocks M, Kon SSC, et al. Sarcopenia in COPD: prevalence, clinical correlates and response to pulmonary rehabilitation. Thorax 2015;70:213-8.

10. Odonkor CA, Schonberger RB, Dai F, Shelley KH, Silverman DG, Barash PG. New utility for an old tool: can a simple gait speed test predict ambulatory surgical discharge outcomes?. Am J Phys Med Rehabil. 2013;92(10):849-863. doi:10.1097/PHM.0b013e3182a51ac5.

11. Karege G, Zekry D, Allali G, Adler D, Marti C. Gait speed is associated with death or readmission among patients surviving acute hypercapnic respiratory failure. BMJ Open Respir Res . 2020;7(1):e000542. doi:10.1136/bmjresp-2019-000542.

12. Reeves GR, Forman DE. Gait Speed: Stepping Towards Improved Assessment of Heart Failure Patients. JACC Heart Fail . 2016;4(4):299-300. doi:10.1016/j.jchf.2016.02.002

13. Afilalo J, Eisenberg MJ, Morin JF, et al. Gait speed as an incremental predictor of mortality and major morbidity in elderly patients undergoing cardiac surgery. J Am Coll Cardiol . 2010;56(20):1668-1676. doi:10.1016/j.jacc.2010.06.039.

14. Sawatzky JA, Kehler DS, Ready AE, et al. Prehabilitation program for elective coronary artery bypass graft surgery patients: a pilot randomized controlled study. Clin Rehabil . 2014;28(7):648-657. doi:10.1177/0269215513516475

15. Fontes Cerqueira TC, Cerqueira Neto ML, Cacau LAP, et al. Ambulation capacity and functional outcome in patients undergoing neuromuscular electrical stimulation after cardiac valve surgery: A randomised clinical trial. Medicine (Baltimore) . 2018;97(46):e13012. doi:10.1097/MD.0000000000013012

16. Clegg A, Young J, Iliffe S, Rikkert MO, Rockwood K. Frailty in elderly people. Lancet 2013;381:752-62.

17. Guizilini S, Viceconte M, Esperança GT, et al. Pleural subxyphoid drain confers better pulmonary function and clinical outcomes in chronic obstructive pulmonary disease after off-pump coronary artery bypass grafting: a randomized controlled trial. Rev Bras Cir Cardiovasc . 2014;29(4):588-594. doi:10.5935/16789741.20140047.

18. Patel BK, Hall JB. Perioperative physiotherapy. Curr Opin Anesthesiol. 2013;26(2):152-6.

19. França EET, Ferrari F, Fernandes P, Cavalcanti R, Duarte A, Martinez BP, et al. Fisioterapia em pacientes críticos adultos: recomendações do Departamento de Fisioterapia da Associação de Medicina Intensiva Brasileira. Rev Bras Ter Intensiva. 2012;24(1):6-22.

20. Cordeiro ALL, Mascarenhas HC, Landerson L, Araújo JS, Borges DL, Melo TA et al. Inspiratory Muscle Training Based on Anaerobic Threshold on the Functional Capacity of Patients After Coronary Artery Bypass Grafting: Clinical Trial. Braz J Cardiovasc Surg 2020 - Ahead of print:1-8. doi: 10.21470/1678-97412019-0448.

21. Cordeiro AL, de Melo TA, Neves D, et al. Inspiratory Muscle Training and Functional Capacity in Patients Undergoing Cardiac Surgery. Braz J Cardiovasc Surg. 2016;31(2):140-144. doi:10.5935/1678-9741.20160035.

22. Lal S, Gray A, Kim E, et al. Frailty in Elderly Patients Undergoing Cardiac Surgery Increases Hospital Stay and 12-Month Readmission Rate [published online ahead of print, 2019 Dec 5]. Heart Lung Circ . 2019;S1443-9506(19)31488-X. doi:10.1016/j.hlc.2019.10.007 
23. Castro VMN, Vitorino PVO. Revisão integrativa sobre a fisioterapia na reabilitação cardiovascular no Brasil. Revista EVS-Revista de Ciências Ambientais e Saúde. 2013;40(4):479-487.

24. Aikawa P, Cintra ARS, Oliveira AS, Silva CTM, Pierucci JD, Afonso MS, et al. Reabilitação Cardíaca em Pacientes Submetidos à Cirurgia de Revascularização do Miocárdio. Rev Bras Med Esporte 2014;20(1).

25. Oliveira GU, Carvalho VO, Cacau LPA, Araújo AAF, Cerqueira MLN, Silva WMJS, et al. Determinants of distance walked during the six-minute walk test in patients undergoing cardiac surgery at hospital discharge. Journal of Cardiothoracic Surgery 2014;9:95.

26. Borges DL, Silva MG, Silva LN, Fortes JV, Costa ET, Assunção RP, et al. \Effects of Aerobic Exercise Applied Early After Coronary Artery Bypass Grafting on Pulmonary Function, Respiratory Muscle Strength and Functional Capacity: A Randomized Controlled Trial. J PhysAct Health. 2016 Sep.;13(9):946-51.

Figure 1. 10-meter speed test

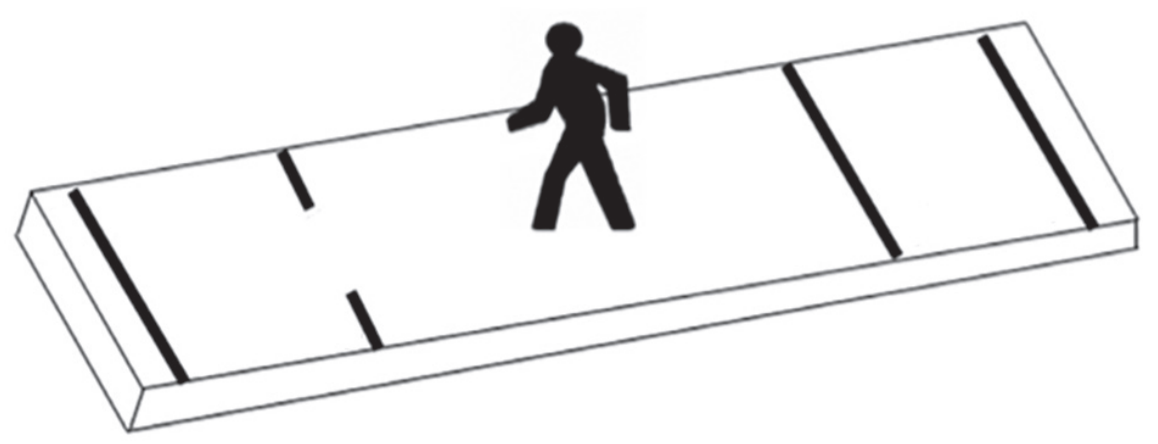

Table 1. Clinical, surgical and functional data of the studied patients.

\begin{tabular}{llll}
\hline Variable & Slow Walk $(\mathrm{n}=20)$ & Non-Slow Walk $(\mathrm{n}=36)$ & $\mathrm{p}$ \\
\hline Gender Male Female & $12(60 \%) 8(33 \%)$ & $22(61 \%) 14(39 \%)$ & $0,72^{\mathrm{a}}$ \\
Age (years) & $60 \pm 9$ & $62 \pm 10$ & $0,53^{\mathrm{b}}$ \\
BMI $\left(\mathrm{kg} / \mathrm{m}^{2}\right)$ & $28 \pm 4$ & $26 \pm 6$ & $0,32^{\mathrm{b}}$ \\
Comorbidities Diabetes & $12(60 \%) 11(50 \%) 11$ & $22(61 \%) 15(42 \%) 20$ & $0,69^{\mathrm{a}} 0,43^{\mathrm{a}} 0,51^{\mathrm{a}} 0,41^{\mathrm{a}}$ \\
Mellitus SAH & $(50 \%) 14(70 \%) 8$ & $(56 \%) 22(61 \%) 14$ & $0,76^{\mathrm{a}}$ \\
Dyslipidemia & $(40 \%)$ & $(39 \%)$ & \\
Sedentary lifestyle AMI & & $7(19 \%) 7(19 \%) 17$ & $0,76^{\mathrm{a}} 0,64^{\mathrm{a}} 0,53^{\mathrm{a}}$ \\
NYHA I II III IV & $4(20 \%) 4(20 \%) 8$ & $(48 \%) 5(14 \%)$ & $0,32^{\mathrm{a}}$ \\
& $(40 \%) 4(20 \%)$ & $90 \pm 22$ & $0,45^{\mathrm{b}}$ \\
CPB time (min) & $88 \pm 20$ & $6 \pm 3$ & $0,58^{\mathrm{b}}$ \\
MV time (hours) & $8 \pm 3$ & $45 \pm 4$ & $0,23^{\mathrm{b}}$ \\
Ejection fraction $(\%)$ & $42 \pm 7$ & $2,6 \pm 0,5$ & $0,66^{\mathrm{b}}$ \\
Number of grafts & $2,4 \pm 0,8$ & & \\
\hline
\end{tabular}

a. Chi-square; ${ }^{\text {B }}$. Independent Student's T test; BMI - Body Mass Index; SAH - Systemic Arterial Hypertension; AMI - Acute Myocardial Infarction; NYHA - New York Heart Associaton; CPB - cardiopulmonary bypass; MV - Mechanical ventilation.

Table 2. Univariate and multivariate associations between predictive variables and readmission

Table 2. Univariate and $n$ Predictor Univariate HR (95\% CI) 
Table 2. Univariate and multivariate associations between predictive variables and readmission

Table 2. Univariate and $\mathrm{n}$

Gait speed

Age

$0.6(0,2$ to 0,9$)$

Male gender

$0.9(0,6$ to 1,3$)$

BMI

$1.1(0,7$ to 1,6$)$

MV time

$1.0(0,9$ to 1,3$)$

CPB time

$1.2(0,8$ to 1.5$)$

$0.9(0,7$ to 1,2$)$

BMI - Body Mass Index; MV - Mechanical Ventilation; CPB - Cardiopulmonary bypass. 